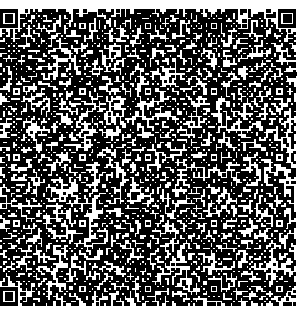

\title{
Implementation of M-government: Leveraging Mobile Technology to Streamline the E-governance Framework
}

Raed Kareem Kanaan, Amman Arab University, Amman, Jordan, rk@aau.edu.jo

Ghassan Abumatar, Amman Arab University, Amman, Jordan, gabumatar@hotmail.com Musa Al-Lozi, The University of Jordan, Amman, Jordan, Lozi.musa@ju.edu.jo

Alhareth Mohammed Abu Hussein, Amman Arab University, Dr.hareth@aau.edu.jo

\section{Abstract:}

Mobile-government (m-government) is the initial stage of the development of the futuristic trends of the e-government. There are several features of advanced technologies of mobile platforms, including smartphone applications, internet facilities; integrated personal computer platforms are promising developments for incorporation into various socio-economic systems. In the same purview, the growth of the technology of m-government has been tremendous. An evolution of the practice of $\mathrm{m}$-government can lead to excellent communication patterns between the government and the voting population. The current study evaluates the various features of m-government, its implementation, the process of general incorporation into the system of governance. This study focuses on the generic challenges surrounding the application of m-governments across different locations in the world, its relevance to the citizens, as well as reviewing the potential requirements and possible challenges in its implementation. This current study reviews existing literature to understand the various benefits of the technology of m-government with the primary focus of this study is to determine the methods of enhancement of government information regardless of the time and location. A detailed review of existing literature pertinent to m-government and compiles the findings on the definition, usability, challenges, and implementation of m-government was conducted. Findings suggest a need for the development of a model for technical, political and social assessment of user intent for adoption for mobile services in particular. It effectively establishes a relationship between various drivers of $\mathrm{m}$-government and user acceptance.

Keywords:

m-government, e-government, mobile, electronic, technology

Citation:

Kanaan, Raed Kareem; Abumatar, Ghassan; Al-Lozi, Musa; Abu Hussein, Alhareth Mohammed (2019); Implementation of M-government: Leveraging Mobile Technology to Streamline the Egovernance Framework; Journal of Social Sciences (COES\&RJ-JSS), Vol.8, No.3, pp:495-508; https://doi.org/10.25255/jss.2019.8.3.495.508.

This work is licensed under a Creative Commons Attribution 4.0 International License. 


\section{Introduction}

Mobile government (m-government) is, in essence, an extension or a subset of the technology of electronic government (e-government). M-government refers to the usage of information and communication technology (ICT) through mobile platforms for various operational and communication needs of the government (Abaza \& Saif, 2015). It is known that focal points of the usage of ICT by governments worldwide include the enhancement communication of services to normal citizens. Furthermore, various technological advancements have been witnessed in recent times. Technological intervention into governmental communication is a major step towards smart governance and digitalization (Mofleh \& Wanous, 2008; Alenezi \& Tarhini, 2015; Alenezi et al., 2017; Kanaan \& Masa'deh, 2018). Additionally, technology has undergone vast evolution, especially in the field of wireless communication. Thereby, various technologies related to mobile platforms of communication are crucial for the development of the patterns of governance as observed across the world.

Rich prospects of $\mathrm{m}$-government have added a potential value to the system of e-governance as the accessibility of information increases manifold due to its compatibility to mobile devices such as smartphones (Ghyasi \& Kushchu, 2004). Any device that is enabled with wireless technologies such as Wi-Fi networks is compatible for usage in the delivery of services of public interest. This further enhances the relevance of the government to the general citizens (Fahad et al., 2018). Visibility and instant delivery of governmental services boost the involvement of the youth into the dynamics of governance (Abaza \& Saif, 2015). A large number of studies on $\mathrm{m}$-government tools have focused primarily on the implementation of this technology from the perception of developed nations. Implementation of the technology can vary between the contexts of developed and third-world nations due to the considerations of infrastructure, digitalization, and awareness of the citizens about the digital platform. M-government has been successfully executed in European countries (Alssbaiheen \& Love, 2015). Research also emphasizes the context of nations where $\mathrm{m}$-government is already implemented and under use.

One main focus of this research has been the dynamics of nations where the delivery of services using $\mathrm{m}$-government systems is currently ongoing. Therefore, the considerations for the successful fresh implementation in countries where it has not been practiced remain out of the purview of literature (Jotischky \& Nye, 2012). Particular reference to the provision of governmental services using mobile technology has not been completely evaluated in research. Moreover, researchers primarily focus on implementing these services in various sectors, including banking, education, transport etc. Organized induction of $\mathrm{m}$-government has to be reviewed about the appropriate implementation and the usability of mobile technologies to aid the delivery of services to citizens through the mobile platform (Alssbaiheen \& Love, 2015).

Data with open accessibility has experienced a steep growth in recent times owing to its enhanced usage in various sectors. Thereby, this has laid an unprecedented pressure on various organizations of public service and sectors for the release of raw data of their deliverables (Janssen, Charalabidis, \& Zuiderwijk, 2012). M-government prospects can be extended to the development and management of people. This is a topic of discussion in the context of developing or third-world countries (Karajeh \& Maqableh, 2014; Al-Hubaishi, Ahmad, \& Hussain, 2017). In countries like Sub-Saharan Africa, the development of the penetration of technologies of mobile phone and mobile technologies are a subject of research (Asongu \& Nwachukwu, 2016). There has been a drastic transformation in the pattern of utilization of technology and the various opportunities that are available for the delivery of services of the government to the public (Ahmad, Ansari, Akhtar, \& Parveen, 2014). Several countries have been able to implement mobile service delivery with huge success. Proactive 
dynamics of communication between the government and the public have undergone a massive improvement in recent times (Abu-Shanab \& Haider, 2015). Mobile technology provides a significant upsurge in the utilization of technology as it provides the necessary opportunity of access to public services regardless of the location and the time of access. Therefore, it works to the advantage of the community of users, thereby greatly facilitating the communication patterns between the government and the citizens (Weerakkody, Irani, Lee, Osman, \& Hindi, 2015). Communication through the platform of mobile phones, especially communications through SMS is of great help as they allow for access at any time and place (Abu-Shanab \& Haider, 2015). Psychosocial perceptions and the user attitudes to ICT and $\mathrm{m}$ government play a critical role in the success of adoption of m-government. To benefit the public, these technologies need to be implemented. Additionally, the factors of perceived usability, ease of access, and attitudes of the users play a vital role in understanding the potential usage of the technology (Abu-Shanab \& Haider, 2015).

Since the initial introduction during the 1990s, the overall usability and the technology of egovernment has undergone significant upgradation and changes. Despite a common platform of the types of services provided by different governments, the implementation of the technology has not been homogeneous or singular (Datar, Panikar, \& Farooqui, 2008). A few salient advantages of the adoption of e-governments or the technologies of m-governments include the effectiveness that they render on the factors of time and cost. General processes, delivery, services, technologies, documentation, and monitoring of governmental services and operations are greatly enhanced by the adoption of these services (Datar, Panikar, \& Farooqui, 2008). Ingrained technologies of $\mathrm{m}$-government provide a proactive and enterprising platform for communication between the government and the public (Bertot, Jaeger, \& McClure, 2008). The mobile platform of communication being adopted for the delivery of governmental services is not uniform or homogeneous. There is a variation among the methods of usage of the initiatives of m-government (Ishengoma, Mselle, \& Mongi, 2018). Essential factors of success of the m-government technology and the various implications of the use of $\mathrm{m}$ government issues have been discussed in elaborate detail in several research papers. Potentially, the use of m-government lies in the orbit of environmental benefit as it contributes to the reduction in the usage of paper-based delivery of services (Nkohkwo \& Islam, 2013).

In conventional modes of paper-based delivery of services leads to a great volume of wastage of paper. An electronic mode of delivery facilitates conservation using enhanced communication as well as improved usability of data management. Usage of ICT ensures effective collection, management, and access of data (Altamony et al., 2012; Khwaldeh et al., 2017; Ishengoma, Mselle, \& Mongi, 2018). M-government has a high potential mainly due to the increased number of subscribers of mobile phone services. Effective service delivery, therefore, becomes easy and accessible to the public situated anywhere in the nation. Processes of dynamic and robust communication facilitated between the government and public is an important step in the construction of impeccable administrative and service implementation platforms from the perspective of governance (Dawes, 2008).

Time and technology need to be effectively utilized in terms of data collection and management are one of the most crucial benefits of $\mathrm{m}$-government technology. Furthermore, mass processing of massive volumes of data is facilitated by m-government policies. Collective creation, storage, and utilization of various technologies of communication are greatly impacted by the use of electronic means of service delivery (Dawes, 2008). Additionally, transfer of service delivery also experiences an upsurge in terms of the speeded rate of data delivery to users irrespective of their location or the time of their access. Various services in the purview of m-government can consist of multiple paradigms based on their relevance and 


\section{Journal of Social Sciences (COES\&RJ-JSS), 8(3), pp.495-508}

usage in the public sector. Furthermore, a significant advantage of the use of $\mathrm{m}$-government is its relevance to developing countries owing to the relatively lower cost of implementation (Karan \& Khoo, 2008). Even in developing nations, the number of users of mobile technologies is high. Due to this, the rate of data transfer increases and the delivery of services remotely becomes possible. This leads to quicker data access and limited costs. Developing nations such as India also have depicted a positive attitude and intention of adoption. This is, in fact, a primary step ahead for the prospects of the use of mobile technology in governance (Karan \& Khoo, 2008).

\subsection{Research Gap}

The literature on the current study in recent years lacks an elaborate explanation of the establishment of m-government. This places a priority on previous studies that assess the relationship between e-government and m-government. Research context of developing nations and the specific barriers have been reviewed in a basic realm of computing technology for governance with a lack in discussion specific to mobile technology implementation. Recent research also lacks a detailed assessment of mobile technologies in governance and the specific technological and social challenges to implementation of m-government.

\section{Literature Review}

The transformation of the technological advancements in the fields of communication and information technology has led to the emergence of promising avenues in the field of production, manufacturing, services, and deliverables across various sectors (Tarhini et al., 2015; Tarhini et al., 2017a, b; Yassien \& Mufleh, 2017). The emergence of mobile technologies has also contributed to this progress. Mobile technologies are being used in the government sector is a novel avenue of development (Henning, Janowski, \& Estevez, 2014). Digitalization of government services and deliverables has made a significant contribution to the public sector. Increased ease of access to governmental services makes it a lucrative option. Therefore, the intention of adoption among common users is also high (Prasad, 2012). In nations like India, the growth of m-governance has witnessed considerable growth. Elevated advancements in technology lead to the implementation of government services, which has been an outcome of several initiatives that have been monitored in close context (Kyem, 2016). Consolidation of various fragmented efforts in this respect has led to the development of the technology. Various constituents of the government and the communication of the various services that have to be delivered to the public are being surveyed (Kyem, 2016).

Sustained delivery of government services through the use of $\mathrm{m}$-government methods has relevance to various firms apart from individual citizens (Mengistu, Zo, \& Rho, 2009). Visible seamlessness of data collection, management, and optimization makes the use of $\mathrm{m}$ government an important mode of operation for various governments. Communication using the mobile platform is vast and multivariate. Therefore, m-government is necessarily an emerging trend, even in developing and third-world nations (Mengistu, Zo, \& Rho, 2009).

A study conducted by Schuppan (2009) in the region of Sub-Saharan Africa to identify the trends and the position of m-government, shows that despite the similarity in the initiatives of individual governments, the mode of implementation and the success of the integration of $\mathrm{m}$ government into the social dynamics is not uniform. A primary reason for this is the alterations between the errors and dubious incorporations by various associated personnel. This study has identified the major cause for this as the lack of a comprehensive legislative policy by the government that oversees and regulates the operations (Schuppan, 2009).

Literature has several studies that have examined the various implications of the implementation of m-government in different nations. Research has largely focused on the emergence of m-government as a trend and the various facets of its usability. The most common area of interest of research on the topic of $\mathrm{m}$-government has been to understand 
the success of incorporation in underdeveloped or developing nations including Sub-Saharan Africa, East African regions of Uganda, Tanzania, Rwanda, and Kenya. The usage of mobile technology has been for the delivery of service by the governments and/or as complementary sections for service delivery (Hellström, 2008). Some of the important advantages of the usage of $\mathrm{m}$-government include an elevation in the overall rate of profitability and service delivery. The incorporation of $\mathrm{m}$-government enhances the effective outreach of services to the general public, along with the improved quality of the governmental services (Jahanshahi et al., 2011). The services that are inaccessible to the general public gain increased accessibility with the help of m-government as the availability of mobile services is higher even in regions that lack wired connections or internet and telecommunication media. The services are better accessible to citizens with preferred use of mobile devices due to non-availability of ICT services (Jahanshahi et al., 2011; Aldmour et al., 2017).

2.1. The Drivers of M-government

M-government currently possesses a considerable number of drivers that advocate its implementation. The drivers are inclusive of economic, political, and technical aspects. The implementation of m-government has two primary facets - the drivers that prod the $\mathrm{m}$ government and the likely intention of usage among citizens (Carroll, 2006). The framework provided by the m-government elucidates the context that encourages the comprehension of the main needs of citizens. It has been identified that the drivers of m-government are interconnected and have a mutual relationship of direct reinforcement (Carroll, 2006). The implementation of m-government depends on several factors - the identification of models for the enhancement of potential business growth, provision of the relevant infrastructure, and the effective harnessing of the potential abilities of the available technology. This is carried out by planning various applications and programs that will help in the utilization of the technology (Carroll, 2006). Several factors that drive the m-government implementation have been identified. The primary drivers that urge m-government services include:

- The high popularity and ubiquitous acceptance that has been witnessed for mobile technologies. Mobile phones are widely used in both rural and urban areas, irrespective of the economic and social status (Germanakos et al. 2005). Therefore, the rampant use of mobile phones ensures higher penetrability and outreach of government services. The extent of usage of mobile technology is uniform in the context of developing and developed nations, regardless of age, industry sector, or socio-demographic characters. Mobile technology is, therefore, ingrained in the everyday lives of individuals as a common and inevitable tool of communication (Germanakos et al., 2005).

- The capacities of technology. This is a crucial factor in the determination of the possible limitations of the mobile interface and the capabilities of mobile technology that facilitate the implementation (Borucki et al., 2005).

- The factors include small screen size, limited speed of processing and storage, shortcomings in the efficiency of devices of input and output. Additionally, there can be limitations in the infrastructure that supports mobile technology, including network provisions, software, applications, etc. (Sandy \& McMillan 2005). The correlated protocols and standards are also compromised. There is a likelihood of effecting cascading issues such as quality of data, interoperability between the various channels etc. Also, the transparency of service delivery across the systems of m-government that are paper-based (Borucki et al. 2005). Therefore, for the successful implementation of m-government, several arrangements in terms of governmental legislation for improved privacy and security of information, identification of mobile transactions, and improved infrastructure for the facilitation of smooth functioning of implemented m-government is necessary (Sandy \& McMillan 2005). 
- The various electronic solutions that are developed for the particular use of $\mathrm{m}$-government and the vendors who develop and sell the hardware and the software solutions necessary for the implementation of m-government applications have to be streamlined.

- Business models facilitating the comprehension of value addition to organizations by the implementation of innovative technologies. A wide range of business models that have been devised for the m-government implementation has to be utilized effectively (Elliot 2002). An innate pressure for the adaptation of private-sector business models is present in the public sector. There is, however, an underlying uncertainty of the effectiveness of the application of these models in the real-time scenario (Navarra \& Cornford 2004).

- The sector of telecommunications functioning with the hope of improved prospect of sales and profitability through the widespread transmission of a wider range of content through their concerned network (Carroll, 2006).

The adoption of $\mathrm{m}$-government has witnessed a steep increase in recent times. The reason for this increase is the ease of access and agility of the services. M-government is a popular subset of e-government, where the remote delivery of government services is made available through mobile devices (Schlaeger, 2012). The basic principle of m-government functioning is to make real-time information and service information to citizens. The information is typically customized to the individual and is based on the location. M-government is a reciprocal channel of e-government and does not have the potential to replace e-governance. However, $\mathrm{m}$-government has a higher outreach in terms of penetrability to regions where there is a lack of internet or ICT technology. The level of customization and outreach improve greatly with the use of m-government (Kesavarapu and Choi, 2009). Therefore, m-government is not viewed as a separate and unique 'type' of government but rather as an important component of e-government that acts a 'tool' of operation and reaches out to consumers across the world (El-Kiki and Lawrence, 2007). The salient observations about the feature of m-government were that it is a sub-classification of e-government which has higher accessibility and versatility. Also, it is known to be a more dynamic and efficient system that is accessible to citizens all over the nation regardless of the availability of ICT and internet services. Therefore, $\mathrm{m}$-government is perceived as a tool of e-government that provides access to rural regions as well (Shareef et al., 2012). The potential drivers for the adoption of $\mathrm{m}$-government depend on several factors, including the consumer base, the types of users, and user intentions for adoption. For developed and developing nations, the scenario is different (Datar, Panikar, \& Farooqui, 2008). For developing nations, the drivers primarily include improved connectivity of the government, enhanced cost-effectiveness and management of large savings, innovation in services etc. Additionally, for the integration of employee information and governmental assets anchorage of e-government technology (Datar, Panikar, \& Farooqui, 2008). The process of consolidation has a necessary prerequisite of developing a structured method of governmental hierarchy and organization. For the adoption of $\mathrm{m}$-government of $\mathrm{m}$ government in the context of developing nations, the infrastructure of information processing and delivery of services is the driving factor. Moreover, through the use of models of governance, delivery of services gains higher priority and accessibility, thereby having higher efficiency and are centric to the citizens (Datar, Panikar, \& Farooqui, 2008). A crucial part of the infrastructure development includes the formulation of specific policies, regulations, standards, and laws. In the developed nation context, assessment drivers for m-government are not of crucial priority due to its existing success in adoption (Datar, Panikar, \& Farooqui, 2008).

\subsection{M-Government Adoption}

Digitalization of governmental services is a great step forward for the advancements in the adoption of delivery of services and the necessary role of technology in facilitating improved 
communication and service delivery. The adoption of $\mathrm{m}$-government is possible through the incorporation of various technological advancements in the field of information and communication (Kumar, 2017). In highly populous nations with a status of developing progress, several considerations need to be made before the effective implementation of $\mathrm{m}$ government. The services have to be made available to the large population with limited infrastructure in countries like India, Pakistan, and Sri Lanka. The competence of the availability of internet and services that are important for the incorporation of m-government into the social and political scenario needs to be considered with great caution (Prasad, 2012). Various strategies need to be implemented for the application of $\mathrm{m}$-government into an existing political scenario. In Asian countries, the irregularity of developed between each different nation is prominent. Therefore, the adoption of $\mathrm{m}$-government has to be specifically designed for each nation and its specific political scenario (Karan \& Khoo, 2008). The framework for a majority of factors that are considered for the adoption of m-government scale the parameters of the relationship between technology and development. The various strategies for the successful adoption of m-government, therefore, include investment in infrastructure. The government needs to make necessary investments in infrastructure to support the development of the m-government service delivery. It is essential to ensure effective management of the factors of infrastructure (Ebrahim \& Irani, 2005). Infrastructural preparedness is considered as one of the most important factors for the successful adoption of m-government. The provision of mobile services to regular citizens is considered a step forward (Rahul \& Sen, 2004).

Communication of information across the source of technological applications is crucial for the success of $\mathrm{m}$-government in the private sector, apart from social relevance. To increase the social awareness and acceptance of m-government, the availability of technological resources and infrastructure is important (Karan \& Khoo, 2008). The limited usage of internet due to low availability of broadband services is an important precursor for the adoption of $m$-government. Therefore, the telecommunication sector is an important contributor to the effective adoption of m-government. Mobile technologies are easily accessible, even in vernacular languages. Thus, ensuring enhanced accessibility (Karan \& Khoo, 2008).

\subsection{Impact of M-government}

M-government provides a wide range of opportunities for the government with enhanced outreach to the citizens. The relative importance of information and communication technology pervading the everyday lives of individuals plays the role of a crucial determiner in the adoption of m-government (Kyem, 2016). In the delivery of m-government services, elementary services of text and voice messaging are used widely. In mobile technology, the effectiveness of the propagation, processing, storage, and organization of data is considerably high. Furthermore, the direct flow of information between the government and citizens ensures good governance with the virtues of transparency and accountability (Kyem, 2016). Primarily, salient contributions or impacts of m-government are as follows:

- Improved Accessibility: For better access to the government, the utilization of m-government is rendered. Rate of penetration of m-government into the lives of the public is witnessing a constant increase. Regardless of time and location, the accessibility of information is possible. The services have high mobility and availability.

- Enhanced outreach: Most citizens have easy access to mobile phones and use them regularly. Therefore, the outreach of government services using the mobile platform is enhanced.

- Adoption: The adoption of $\mathrm{m}$-government is likely to be viewed as a natural process owing to the extent of integration of mobile technology into the everyday lives of people. The ease of access and increased mobility ensure higher levels of adoption (Hellstrom, 2008). 
- Higher interactiveness and facilitation of communication: The mode of communication has higher interactiveness due to the effective interactive dialogue in contrast to a one-way information conveyance through more traditional methods of speeches and advertising (Kyem, 2016).

- Cost-effectiveness: Applicability of mobile technology for governance has effective cost management. Due to the lower infrastructure requirements, utilization of mobile technology is easy and cost-effective (Kushchu \& Kuscu, 2004).

- Efficiency: Technology has a higher outreach and increased adoption rate. Mobile phones usage render great interaction in real-time scenarios.

- The best mode of communication: In most nations of poor infrastructure, the availability of mobile technologies is the highest, due to which, it makes for the well-founded and the best mode for e-governance. Most countries lack internet and ICT access in uniformity (Borucki et al., 2005).

2.4. Challenges for Implementing Mobile Government in Developing Countries

Notwithstanding the great potential and wide opportunities provided by the mobile platform, there are several challenges in the adoption of m-government in developing countries. The utilization of $\mathrm{m}$-government policies in developing nations include the potential barriers and challenges that are likely to be faced in its adoption (Kyem, 2016). There is an observed increase in the subscription rate of mobile technology (Scott \& Golden, 2009). The growth in the number of subscribers of mobile phones is mainly due to irrelevance or the removal of alternate traditional means of communication such as posts, fixed phone lines, and manual communication. In developing nations, even in sub-Saharan Africa, there are several challenges despite its proven beneficial:

- Technical challenges: The establishment of government services and governance framework at large in the mobile interphase is extremely complex and challenging. Services and governance have a complex structure which cannot be incorporated into the base-level platform of mobile phones (Germanakos et al., 2005). The challenges include limited texting capacity, lower display, and small screen size, among others. In rural areas where high-end mobile phones are not available, a considerable number of features of m-government are removed (Kyem, 2016).

- Irregular technological access: The cost of hardware and software technologies is considerably high. The disparity in economic statuses among citizens also causes a disparity in ownership of services. Most citizens are unable to afford the network and mobile subscription rates that are not entirely regulated. To mention specifically, wireless coverage among the marginalized communities is still lacking (Kyem , 2016).

- Lack of resources or oversights: The accountability of services and the provisions provided by the government need to be reviewed essentially in terms of authenticity and ease of access (Kaylor et al., 2001). In nations that do not follow democracy, an authoritative tendency may be observed in m-government, e.g. sub-Saharan Africa (Kyem, 2016).

- Privacy concerns: The increased interaction between citizens and the government leads to concerns in privacy issues. This leads to information exchange between citizens and the government. Personal privacy is challenged in situations of totalitarian types of government (Kyem, 2016).

- Lack of proactive involvement of citizens: The potential success of m-government implementation depends on the extent of acceptance by citizens. The acceptance is not limited to the citizens alone but also includes governmental employees, employees of the business sector, and the involved public sector bodies. In cases of lack of proactive participation of these entities and individuals, the success of m-government is not likely (Hellstrom, 2008).

- The tendency of despotism: In countries that do not follow democracy, the chances of the government developing despotic or authoritative tendencies is pronounced. These challenges 
can pose a threat to the rights of common citizens. The adoption of $\mathrm{m}$-government must focus on avoiding this barrier (Hellstrom, 2008).

\subsection{Conceptual Framework}

Literature about m-government and adoption of service delivery through mobile technology has proposed several models of a conceptual framework. The most pertinent and popular of these models is the technology acceptance model (TAM) (Davis, 1989) and the theory of reasoned action (TRA) (Fishbein \& Ajzen, 1975).

The model of TAM is widely accepted in the research about information systems or IS. TAM is used for the analysis of the acceptance of mobile systems for governance issues. The older models in literature have focused on acceptance of computing technology, rather than mobile technologies. Therefore, it is important to study the acceptance of mobile technologies using these models (Gao, Krogstie, \& Gransæther, 2008). An extended model of TAM, known as the mobile services acceptance model (MSAM), has been proposed that it is important for the analysis of acceptance of mobile technologies. This model is developed based on perceived usefulness factor, characteristics, personal initiatives, context, and trust (Gao et al., 2008). Context refers to the mobile context, information of historical context, and the features of environmental consequence are studied in the MSAM. The personal initiatives refer to various elements of technology, including technological preferences and personal level of knowledge about a topic (Ishengoma, Mselle, \& Mongi, 2018). Personal skills of usage of technology and knowledge determine the ease of adoption of the services offered through m-government (Gao et al., 2008).

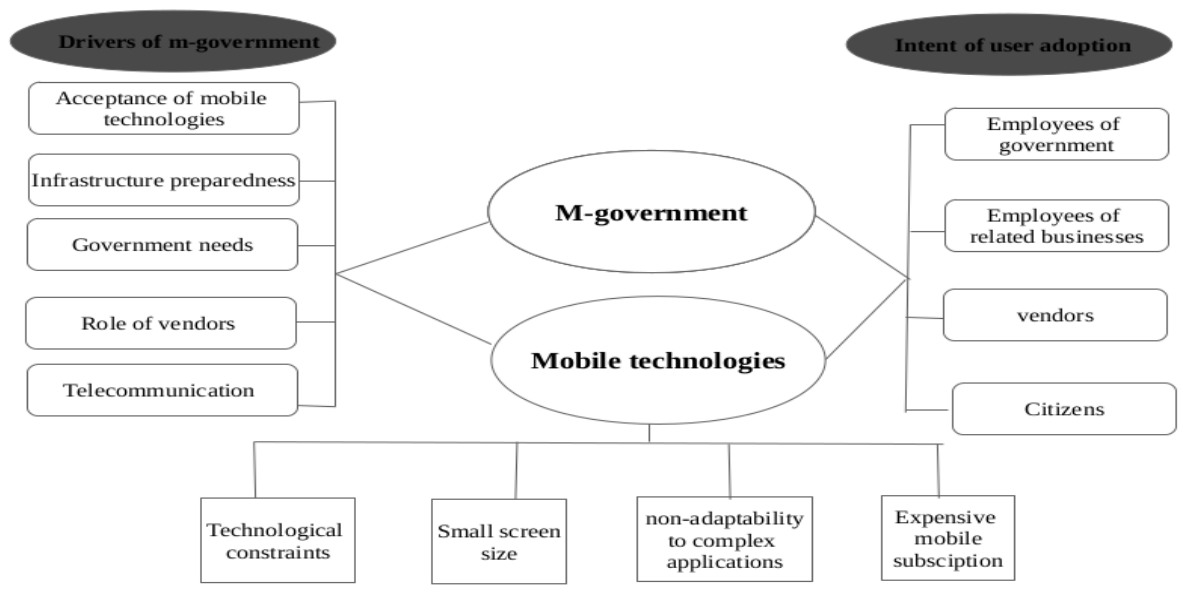

The left-hand side of the framework provides the various drivers for $\mathrm{m}$-government. These include the acceptance of mobile technologies, the specific needs of the government, vendors, and role of the telecommunication sector in the development of the m-government (Saadi, Ahmad, \& Hussain, 2017). The right-hand side provides a list of parties who are influenced by the implementation along with reviewing their specific intentions of use.

Several factors are responsible for effective incorporation of $\mathrm{m}$-government into the public arena. These are termed "drivers", which this study regards as independent variables. Drivers of m-government have a considerable and variegated impact on functionalities of $\mathrm{m}$ government. Subsequently, the intention of users and attitudes towards the adoption of $\mathrm{m}$ government is affected (Gao et al., 2008). Conceptual evaluation of these parameters and their interdependence is reflected in this study. Findings indicate a direct dependence relationship 
between dependent and independent variables. Dependent variables that are identified such as telecommunication companies, business vendors, specific governmental needs etc. directly influence patterned adoption of $\mathrm{m}$-government. In turn, these parameters influence various user attitudes in that if $\mathrm{m}$-government is implemented effectively, user attitudes experience a positive change (Gao et al., 2008).

\section{Conclusion}

Prospects of m-government involve the analysis of several considerations, across variegated planes. Considerations include social, political, and technological features of the context of adoption. Although the platform of mobile technologies is one of the most widely used, there are several challenges in the adoption of government services into the mobile interface. Several issues regarding the complexity of government services, authoritarian attitudes, and complex availability factors have widely been discussed in the literature. Additionally, mobile transactions purview includes privacy issues apart from governmental regulations. These can pose a threat to the personal privacy of citizens. The mobile platform is compromised technologically in terms of the lower level of sophisticated equipment, smaller screen size, lack of complex technological platforms etc. Existing literature is reviewed, focusing the definition of $\mathrm{m}$-government along with elucidating the various considerations surrounding its adoption. In the current study, aspects of contextual reference are scaled using assessing the implementation in developing nations in contrast to developed nations. Additionally, studies that have discussed the various drivers of m-government, its features, and level of acceptance among individual citizens. Current paper focus also lies on the considerations surrounding potential barriers and challenges in the context of developing nations. A brief review of models of a conceptual framework to carry out the assessment is also done in the current study. TAM models have previously concentrated on assessing the intention of adoption for computing technologies only. While the MSAM version developed by Gao et al. (2008) focuses on the use of mobile technology for the assessment of the intent of user adoption of mobile services. Since the adoption of m-government needs to be made in the interest of citizens, it is imperative to review carefully the various considerations and challenges surrounding its adoption. Issues of user intent for adoption, mobile interface, mobile subscription rate etc. have been linked to the potential benefit of $m$-government. However, the literature is divided in its views on the usability of m-government. Mobile technology outreach is higher as compared to broadband or computing technologies. However, the complexity of the adoption of government services into the mobile platform and the constraints of interaction through mobile medium have not been completely designated in the existing literature. Thereby, the lack of concrete evidence about either the potential usage or disadvantages in terms of technological, social, and political respects is the primary reason for this divide. In the purview of m-government, the advancement of technological discussion includes the analysis of the factors of adoption such as infrastructural preparedness, user intent for adoption, and the compliance of government and related business employees. Also, there is pressure on the public sector to utilize the models developed by the private sector. Therefore, the current study evaluates existing research in the literature to understand the various drivers, features, challenges, and modalities of m-government.

\section{References}

Abaza, M., \& Saif, F. (2015). The adoption of mobile government services in developing countries. International Journal of Computer Science Issues (IJCSI), 12(1), 137. 
Ahmad, T., Ansari, A.A., Akhtar, A., \& Parveen, S. (2014). Current review of ICT and mgovernment services in Saudi Arabia. International Journal of Computer Engineering and Applications, 7(2), 71-77.

Aldmour, R., Hammdan, F., Dmour, H., Alrowwad, A., \& Khwaldeh, S. (2017). The effect of lifestyle on online purchasing decision for electronic services: the Jordanian flying e-tickets case. Asian Social Science, 13(11), 157-169.

Alenezi, H., \& Tarhini, A. (2015). Investigating the strategic relationship between information quality and e-government benefits: a literature review. International Review of Social Sciences and Humanities, 9(1), 33-50.

Alenezi, H., Tarhini, A., Alalwan, A., \& Al-Qirim, N. (2017). Factors affecting the adoption of egovernment in Kuwait: a qualitative study. Electronic Journal of e-Government, 15(2), 84-102.

Al-Hubaishi, H.S., Ahmad, S.Z., \& Amp; Hussain, M. (2017). Exploring mobile government from the service quality perspective. Journal of Enterprise Information Management, 30(1), 4-16.

Alotaibi, S., \& Roussinov, D. (2017). User acceptance of m-government services in Saudi Arabia: an SEM approach. In The Proceedings of 17th European Conference on Digital Government $\operatorname{ECDG}$ (p.10).

Alssbaiheen, A., \& Love, S. (2015). M-government adoption in Saudi Arabia: challenges and opportunities. International Journal of Technology and Human Interaction (IJTHI), 11(3), 51-68.

Altamony, H., Alshurideh, M., \& Obeidat, B. (2012). Information systems for competitive advantage: implementation of an organizational strategic management process. Proceedings of the 18th IBIMA Conference on Innovation and Sustainable Economic Competitive Advantage: From Regional Development to World Economic, Istanbul, Turkey, 9th-10th May.

Bertot, J.C., Jaeger, P.T., \& McClure, C.R. (2008). Citizen-centred e-government services: benefits, costs, and research needs. In Proceedings of the 2008 international conference on digital government research, Montreal, Canada-May 18 - 21, 2008 (pp. 137-142).

Borucki, C., Arat, S., \& Kushchu, I. (2005). Mobile government and organizational effectiveness. Proceedings of the First European Conference on Mobile Government, Brighton, UK: Mobile Government Consortium International, 56-66.

Carroll, J. (2006). What's in it for Me?. Taking m-government to the people. BLED 2006 Proceedings, 49. http://aisel.aisnet.org/bled2006/49

Datar, M., Panikar A., \& Farooqui, J. (2008). Emerging trends in e-government. Foundations of e-government (pp. 37-46). India: Computer Society of India. Retrieved from http://www.csisigegov.org/critical_pdf/4_37-46.pdf.

Dawes, S.S. (2008). The evolution and continuing challenges of e-governance. Public Administration Review, 68, S86-S102. 
Ebrahim, Z., \& Irani, Z. (2005). E-government adoption: architecture and barriers. Business Process Management Journal, 1(5), 589-611.

El-Kiki, T., \& Lawrence, E. (2007). Mobile user satisfaction and usage analysis model of mgovernment services. Proceedings of the Second European Conference on Mobile Government, EURO mGOV 2006, United Kingdom, pp.91-102.

Elliot, S. (2002). Introduction to B2C strategies and models, in Elliot, S. (ed) Electronic Commerce: B2C Strategies and Models, John Wiley \& Sons, UK.

Fahad, S., Al-Obthani, F., Ameen, A., Saleh, N., \& Alrajawy, I. (2018). Proposing SMARTgovernment model: theoretical framework. International Journal of Management and Human Science (IJMHS), 2(2), 27-38.

Gao, S., Krogstie, J., \&Gransæther P.A. (2008). Mobile services acceptance model. In Proceedings of the 2008 International Conference on Convergence and Hybrid Information Technology, 446-453, Washington, DC, USA.

Gao, S., Krogstie, J., \& Siau, K. (2014). The adoption of mobile games in China: an empirical study. Mobile Information Systems, 10(2), 147-171.

Germanakos, P., Samaras, G., \& Christodoulou, E. (2005). Multi-channel delivery of service-the road from eGovernment to mGovernment. Proceedings of the First European Conference on Mobile Government, Brighton, UK: Mobile Government Consortium International, 210-220.

Ghyasi, F., \& Kushchu, I. (2004). M-government: cases of developing countries. Proceedings of the 4th European Conference on E-Government, Castle Dublin, Ireland.

Hellström, J. (2008). Mobile phones for good governance-challenges and way forward. Draft discussion paperStockholm University/UPGRAID.

Henning, F., Janowski, T., \& Estevez, E. (2014). Towards a conceptual framework for mobile governance for sustainable development (MGOV4SD): reviewing the literature and state of the art in an emerging field. In 2014 European Group for Public Administration (EGPA) Annual Conference.

Ishengoma, F., Mselle, L., \&Mongi, H. (2019). Critical success factors for m-Government adoption in Tanzania: a conceptual framework. The Electronic Journal of Information Systems in Developing Countries, 85(1), e12064.

Jahanshahi, A., Khaksar, S., Yaghoobi, N., \& Nawaser, K. (2011). Comprehensive model of mobile government in Iran. Indian Journal of Science and Technology, 4(9), 1188-1197.

Janssen, M., Charalabidis, Y., \&Amp; Zuiderwijk, A. (2012). Benefits, adoption barriers and myths of open data and open government. Information Systems Management, 29(4), 258-268.

Kanaan, R., \& Masa'deh, R. (2018). Increasing citizen engagement and participation through eGovernment in Jordan. Modern Applied Science, 12(11), 225-231. 
Karan, K., \& Khoo, M.C.H. (2008). Mobile diffusion and development: Issues and challenges of m-government with India in perspective. In Proceedings of The 1st International Conference on M4D Mobile Communication Technology for Development: 11-12 December, 2008, Karlstad University, Sweden.

Kaylor, C., Deshazo, R., \& Van Eck, D. (2001). The essence of e-governance: the enhanced value for stakeholders through transformation: gauging e-government: a report on implementing services among American cities. Government Information Quarterly, 18, 293-307.

Kesavarapu, S., \& Choi, M. (2009). A theoretical framework of knowledge management in mgovernment. Int. Journal of Computer and Communication Technology, 1(1), 3-13.

Karajeh, H., \& Maqableh, M. (2014). Security of cloud computing environment. The 23rd IBIMA Conference on Vision 2020: Sustainable Growth, Economic Development, and Global Competitiveness, USA, 2202-2215.

Khwaldeh, S., Al-Hadid, I., Masa'deh, R., \& Alrowwad, A. (2017). The association between eservices web portals information quality and ICT competence in the Jordanian universities. Asian Social Science, 13(3), 156-169.

Kumar, M., \& Sinha, O. (2007). M-government for e-government. In Proceedings of International Conference on e-Government, India, 294-301.

Kumar, T.V. (2017). E-democracy for smart cities. Singapore: Springer.

Kushchu, I., \& Kuscu, M.H. (2004). From e-government to m-government: facing the inevitable. URL http://www.mgovernment.org/resurces/mgovlab_ikhk.pdf. (2009-03-15).

Kyem, P.A.K. (2016). Mobile phone expansion and opportunities for e-governance in subSaharan Africa. The Electronic Journal of Information Systems in Developing Countries, 75(1), 1-15.

Lam, W. (2005). Barriers to e-government integration. Journal of Enterprise Information Management, 18(5), 511-530.

Mengistu, D., Zo, H., \& Rho, J. J. (2009). M-government: opportunities and challenges to deliver mobile government services in developing countries. In 2009 Fourth International Conference on Computer Sciences and Convergence Information Technology (pp. 1445-1450). IEEE.

Mofleh, S., \& Wanous, M. (2008). Understanding factors influencing citizens' adoption of egovernment services in the developing world: Jordan as a case study. Journal of Computer Science, 7(2)1-11.

Navarra, D., \& Cornford, T. (2004). ICT, innovation and public management: governance, models \& alternatives for e-government infrastructures. Proceedings of the 12th European Conference on Information Systems (ECIS 2004), Turku, Finland. 
Nkohkwo, Q.N., \& Islam, M.S. (2013). Challenges to the successful implementation of egovernment initiatives in sub-Saharan Africa: a literature review. Electronic Journal of eGovernment, 11(2), 253-253.

Prasad, K. (2012). E-governance policy for modernizing government through digital democracy in India. Journal of Information Policy, 2, 183-203.

Rahul, D., \& Sen, C. (2004). The complex nature of e-government projects: case study of Bhoomi, an initiative in Karnataka, India.

Saadi, M.R., Ahmad, S.Z., \& Hussain, M. (2017). Prioritization of citizens' preferences for using mobile government services: the analytic hierarchy process (AHP) approach. Transforming Government: People, Process and Policy, 11(3), 476-503.

Sandy, G., \& McMillan, S. (2005). A success model for m-government. Proceedings of the First European Conference on Mobile Government, Brighton, UK: Mobile Government Consortium International, 349-358.

Schlaeger, J. (2012). The role of m-government in Western China development. A Chapter in the Book 'Mobile Information Communication Technologies Adoption in Developing Countries: Effects and Implications', 364-381.

Schuppan, T. (2009). E-government in developing countries: experiences from sub-Saharan Africa. Government Information Quarterly, 26(1), 118-127.

Scott, M., \& Golden, W. (2009). Understanding net benefits: a citizen-based perspective on egovernment success. International Conference on Information Systems, ICIS 2009 PHOENIX.

Shareef, M.A., Archer, N., \& Dwivedi, Y.K. (2012). Examining adoption behavior of mobile government. Journal of Computer Information Systems, 53(2), 39-49.

Tarhini, A., Al-Badi, A., Almajali, M., \& Alrabayaah, S. (2017a). Factors influencing employees' intention to use cloud computing. Journal of Management and Strategy, 8(2), 47.

Tarhini, A., Al-Busaidi, K., Bany Mohammed, A., \& Maqableh, M. (2017b). Factors influencing students' adoption of e-learning: a structural equation modeling approach. Journal of International Education in Business, 10(2), 164-182.

Tarhini, A., Mgbemena, C., \& Trab, MSA. (2015). User adoption of online banking in Nigeria: a qualitative study. Journal of Internet Banking and Commerce, 20(3), 1-8.

Weerakkody, V., Irani, Z., Lee, H., Osman, I., \& Hindi, N. (2015). E-government implementation: a bird's eye view of issues relating to costs, opportunities, benefits and risks. Information Systems Frontiers, 17(4), 889-915.

Yassien, E., \& Mufleh, M. (2017). The Impact of ERP system's usability on enterprise resource planning project implementation success via the mediating role of user satisfaction. Journal of Management Research, 9(3), 49-71. 